\title{
The coronavirus diseases 2019 (COVID-19) pneumonia with spontaneous pneumothorax: a case report
}

\author{
Xiaoxing Chen ${ }^{1 \dagger}$, Guqin Zhang ${ }^{2 \dagger}$, Yueting Tang ${ }^{3}$, Zhiyong Peng ${ }^{4}$ and Huaqin Pan $^{4^{*}}$
}

\begin{abstract}
Background: The outbreak of the novel coronavirus (COVID-19) that was firstly reported in Wuhan, China, with cases now confirmed in more than 100 countries. However, COVID-19 pneumonia with spontaneous pneumothorax is unknown.

Case presentation: We reported a case of 66-year-old man infected with COVID-19, presenting with fever, cough and myalgia; The patient received supportive and empirical treatment including antiviral treatment, anti-inflammatory treatment, oxygen supply and inhalation therapy; The symptoms, CT images, laboratory results got improved after the treatments, and a throat swab was negative for COVID-19 PCR test; However, on the hospital day 30, the patient presented with a sudden chest pain and dyspnea. CT showed a 30-40\% left-sided pneumothorax. Immediate thoracic closed drainage was performed and his dyspnea was rapidly improved. With five more times negative PCR tests for SARS-CoV-2 virus, the patient was discharged and home quarantine.

Conclusion: This case highlights the importance for clinicians to pay attention to the appearance of spontaneous pneumothorax, especially patients with severe pulmonary damage for a long course, as well as the need for early image diagnose $C T$ and effective treatment once pneumothorax occurs.
\end{abstract}

Keywords: COVID-19, SARS-CoV-2 virus, Pneumonia, Pneumothorax

\section{Background}

In late December 2019, an outbreak of the novel coronavirus (COVID-19) that was firstly reported in Wuhan, China, and was characterized as a pandemic by the WHO on March $11[1,2]$. As of April 1, there were about 823, 626 confirmed cases and 40,598 deaths worldwide [3]. Nowadays, the methods for the definitive diagnosis and treatment of patients with mild symptoms have been well established [4], however clinical manifestations, management and prognosis of COVID-19 pneumonia with

\footnotetext{
* Correspondence: phq2012@whu.edu.cn

${ }^{+}$Xiaoxing Chen and Guqin Zhang contributed equally to this work. ${ }^{4}$ Department of Critical Care Medicine, Zhongnan Hospital of Wuhan University, 169 Eastlake Rd., Wuchang district, Wuhan 430071, Hubei province, China

Full list of author information is available at the end of the article
}

complications such as pneumothorax may be much different. In this study, we report a case of COVID-19 pneumonia patient who developed spontaneous pneumothorax, which may provide further evidence for the suggestive management for such patients.

\section{Case presentation}

The patient is a 66-year-old man living in Wuhan, who reported that he had an initial symptom of fever, dry cough and myalgia on January 18, without chills, dyspnea, chest pain, or diarrhea (Fig. 1). Two days later (January 20), he went to the clinic because of suspicious COVID-19 infection. The CT scan showed ground-glass opacities (GGO) in the basal segment of the right lower lobe (Fig. 2). Subsequently, a throat swab was obtained, and the patient was confirmed of COVID-19 infection

C The Author(s). 2020 Open Access This article is licensed under a Creative Commons Attribution 4.0 International License, which permits use, sharing, adaptation, distribution and reproduction in any medium or format, as long as you give appropriate credit to the original author(s) and the source, provide a link to the Creative Commons licence, and indicate if changes were made. The images or other third party material in this article are included in the article's Creative Commons licence, unless indicated otherwise in a credit line to the material. If material is not included in the article's Creative Commons licence and your intended use is not permitted by statutory regulation or exceeds the permitted use, you will need to obtain permission directly from the copyright holder. To view a copy of this licence, visit http://creativecommons.org/licenses/by/4.0/ The Creative Commons Public Domain Dedication waiver (http://creativecommons.org/publicdomain/zero/1.0/) applies to the data made available in this article, unless otherwise stated in a credit line to the data. 


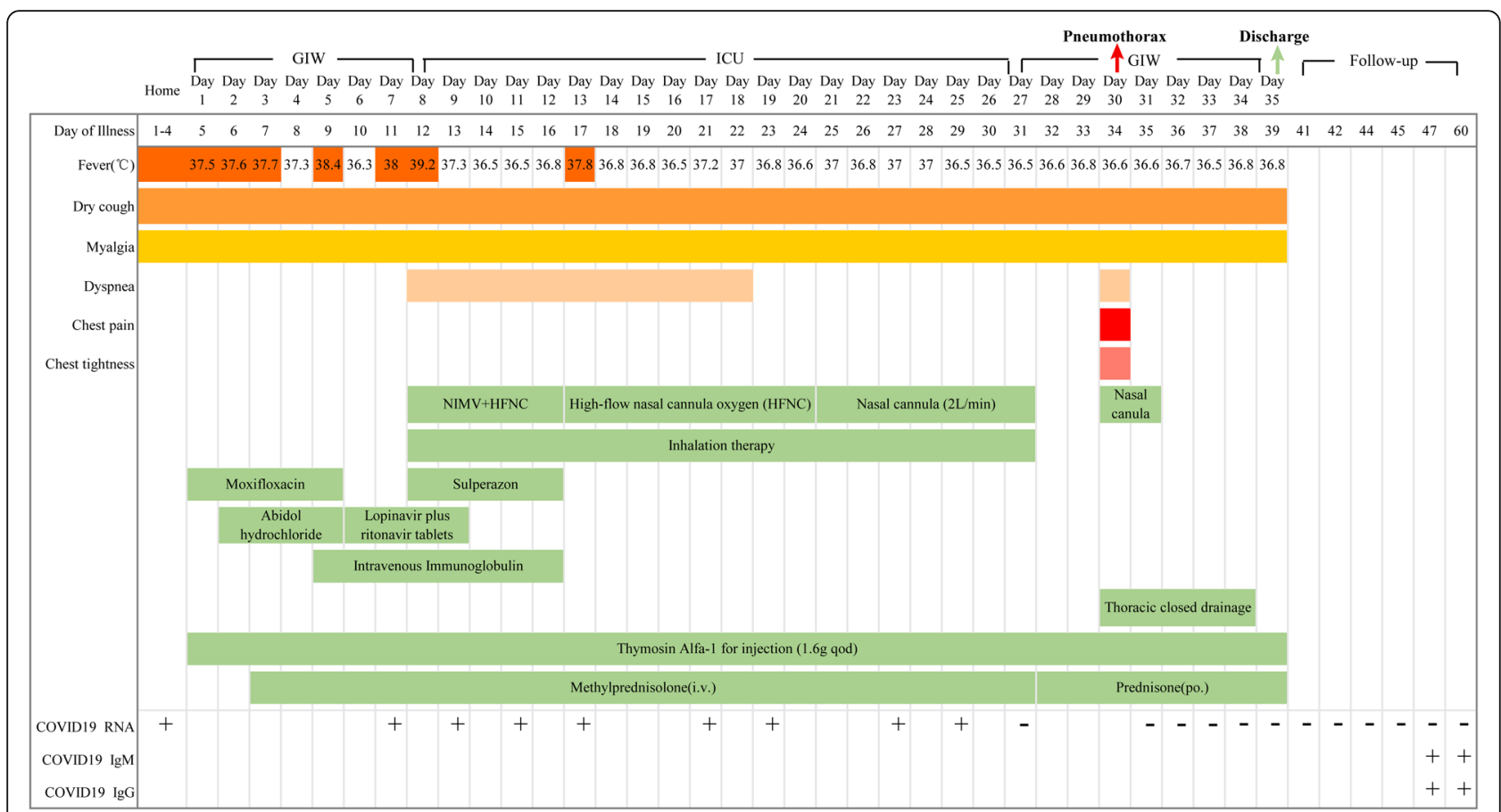

Fig. 1 Timeline of disease course according to days from symptom onset, days from admission, and days of follow-up. from Jan 18-Mar 17, 2020. NIMV, non-invasive mechanical ventilation

by the reverse real-time PCR assay on January 21.On day 5 of illness onset, he was admitted to the general isolation ward (GIW) in Zhongnan Hospital of Wuhan University. The patient did not have a history of any underlying pulmonary disease, which were important on the incidence of spontaneous pneumothorax, such as COPD, cystic pulmonary fibrosis, interstitial lung disease, CTD or asthma; Physical examination revealed a body temperature of $36.3^{\circ} \mathrm{C}$, the blood pressure of $126 /$ $75 \mathrm{mmHg}$, a pulse of 71 beats per minute, the respiratory rate of 17 breaths per minute. Laboratory results were summarized as follows:

The lymphocyte count and percentage continuedly decreased (Table 1).

The neutrophils were initially normal but elevated on day 11 of illness onset (Table 1).

The level of serum procalcitonin was normal (Table 1).

The hepatic function measures were normal (Table 1).

The follow-up CT scan (day 9 of illness) showed multiple patchy ground-glass shadows in the lower lobe of both lungs, which indicated the progression.

The treatment in GIW was basically supportive and empirical. He was given lopinavir plus ritonavir $(500 \mathrm{mg}$ twice daily, po.) and abidol hydrochloride (200 mg three times daily, po.) as antiviral therapy, and moxifloxacin (400 mg once daily, i.v.) to prevent secondary infection. To attenuate lung inflammation, low dose of methylprednisolone (40 mg once daily, i.v.) and intravenous immunoglobulin (20 g once daily for 5 days, i.v.) was administered.

The patient's symptoms continued unabated. On the day 12 of illness, the patient suddenly developed dyspnea with a higher fever of $39.2^{\circ} \mathrm{C}$ and a decreased oxygen saturation value of $80 \%$. He was immediately transferred to the Intensive Care Unit (ICU) and received discontinued non-invasive mechanical ventilation (NIMV) plus high-flow nasal cannula (HFNC) oxygen therapy. The initial $\mathrm{FiO} 2$ for $\mathrm{HFNC}$ was $100 \%$, and maintained with a gas flow-rate of $50 \mathrm{~L} / \mathrm{min}$. A model of continuous positive airway pressure-pressure support ventilation (CPAP/ PSV) for NIMV was intermittently conducted with an adjustable $5-12 \mathrm{cmH}_{2} \mathrm{O}$ positive end expiratory pressure (PEEP). The methylprednisolone dose was elevated to $80 \mathrm{mg}$ every $12 \mathrm{~h}$, and intravenous immunoglobulin was administered for five days. Given the increased neutrophils and the procalcitonin level as shown in Table 1, we started the treatment with cefoperazone sulbactam sodium (3 $\mathrm{g}$ every $8 \mathrm{~h}$, i.v.). Besides, inhalation therapy (Budesonide Suspension $1 \mathrm{mg}$, Ipratropium Bromide Solution $500 \mu \mathrm{g}$ plus Salbutamol Sulfate $5 \mathrm{mg}$, every $6 \mathrm{~h}$, inh.) was given to dilate bronchioles. After receiving medications, the patient's oxygen saturation value increased to $94 \%$. Laboratory results were listed in Table 1. On the day 17 of illness, the patient's clinical condition improved and received HFNC therapy without NIMV. The methylprednisolone was gradually decreased 


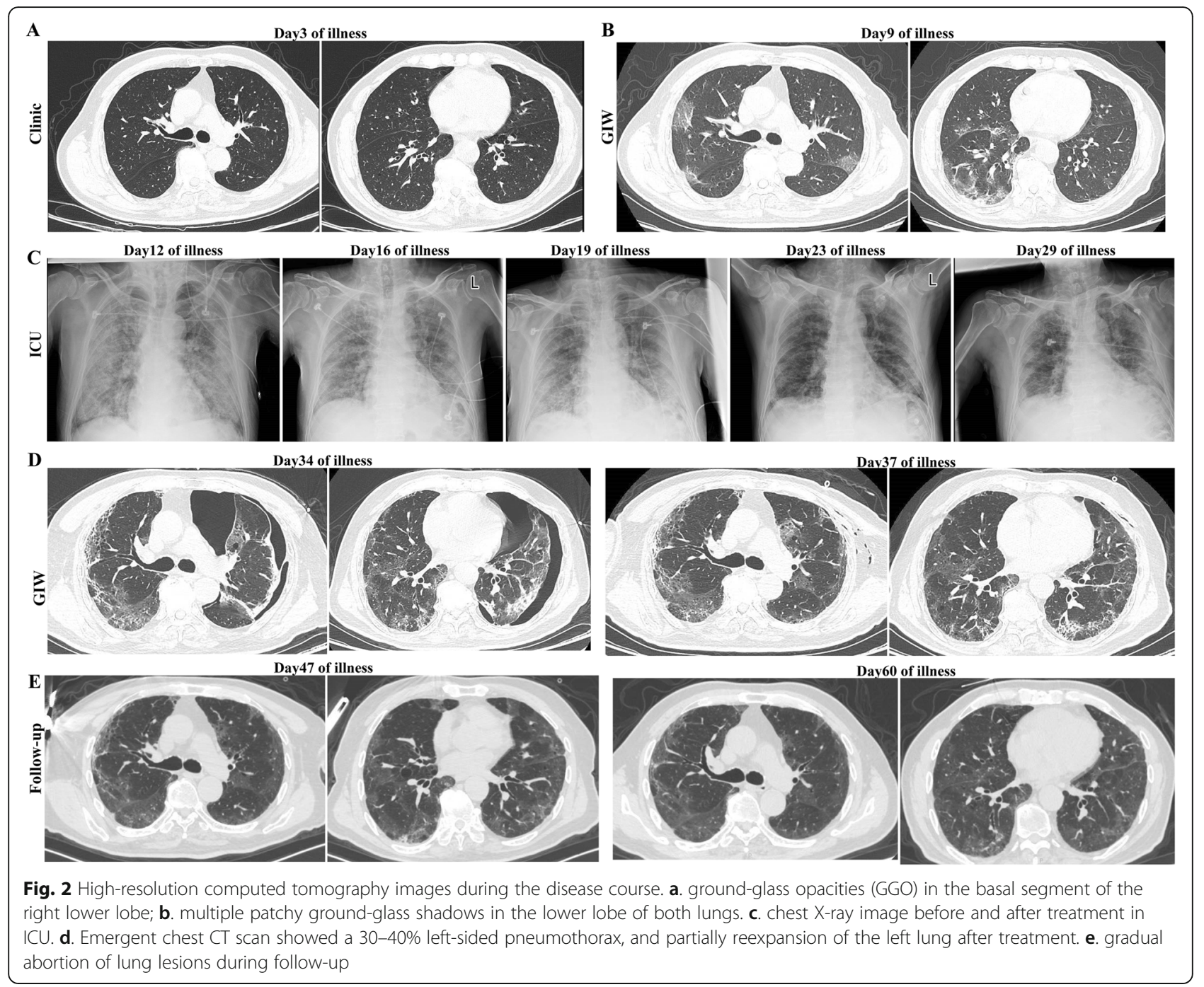

to $20 \mathrm{mg}$ twice daily, and the supplemental oxygen delivered by nasal cannula at 21 per minute was started on day 25 of illness, which maintained the oxygen saturation value above $96 \%$. On day 31 of illness, a throat swab was negative for COVID-19 PCR test. Chest X-ray showed diffuse patchy shadows in both lungs, but the shadows were improved. Hence, the patient was transferred to GIW.

In GIW, methylprednisolone was discontinued and prednisone ( $20 \mathrm{mg}$ twice daily, orally) was administered for anti-inflammatory treatment. Supplemental oxygen was discontinued, and his oxygen saturation value maintained above $94 \%$ when he was breathing ambient air. On the hospital day 30, the patient presented with a sudden chest pain, with dyspnea and chest tightness. Emergent chest CT showed a 30-40\% left-sided pneumothorax. Immediate thoracic closed drainage was performed and his dyspnea was rapidly improved. The supplemental oxygen was delivered by nasal cannula at 21 per minute.
Subsequent CT showed partially reexpansion of the left lung, with little free air in the left thorax. There were multiple patchy ground-glass density pulmonary infiltrates and fibrosis in both lungs. The chest tube was extracted on the hospital day 34 (day 38 of illness). The patient remained afebrile for more than twenty days, and all symptoms have resolved except myalgia, which was decreased in severity. With five more times negative PCR tests for SARS-CoV-2 virus, the patient was discharged and home quarantine.

\section{Discussion and conclusion}

Latest studies have revealed that the COVID-19 shares over $88 \%$ homology with two bat-derived severe acute respiratory syndrome (SARS)-related coronaviruses [5]. Research for SARS outbreak in 2003 demonstrated that spontaneous pneumothorax is complicated with a rate of $1.7 \%$ in critically ill cases [6].. Severe pulmonary lesions may predispose to spontaneous pneumothorax. Without 


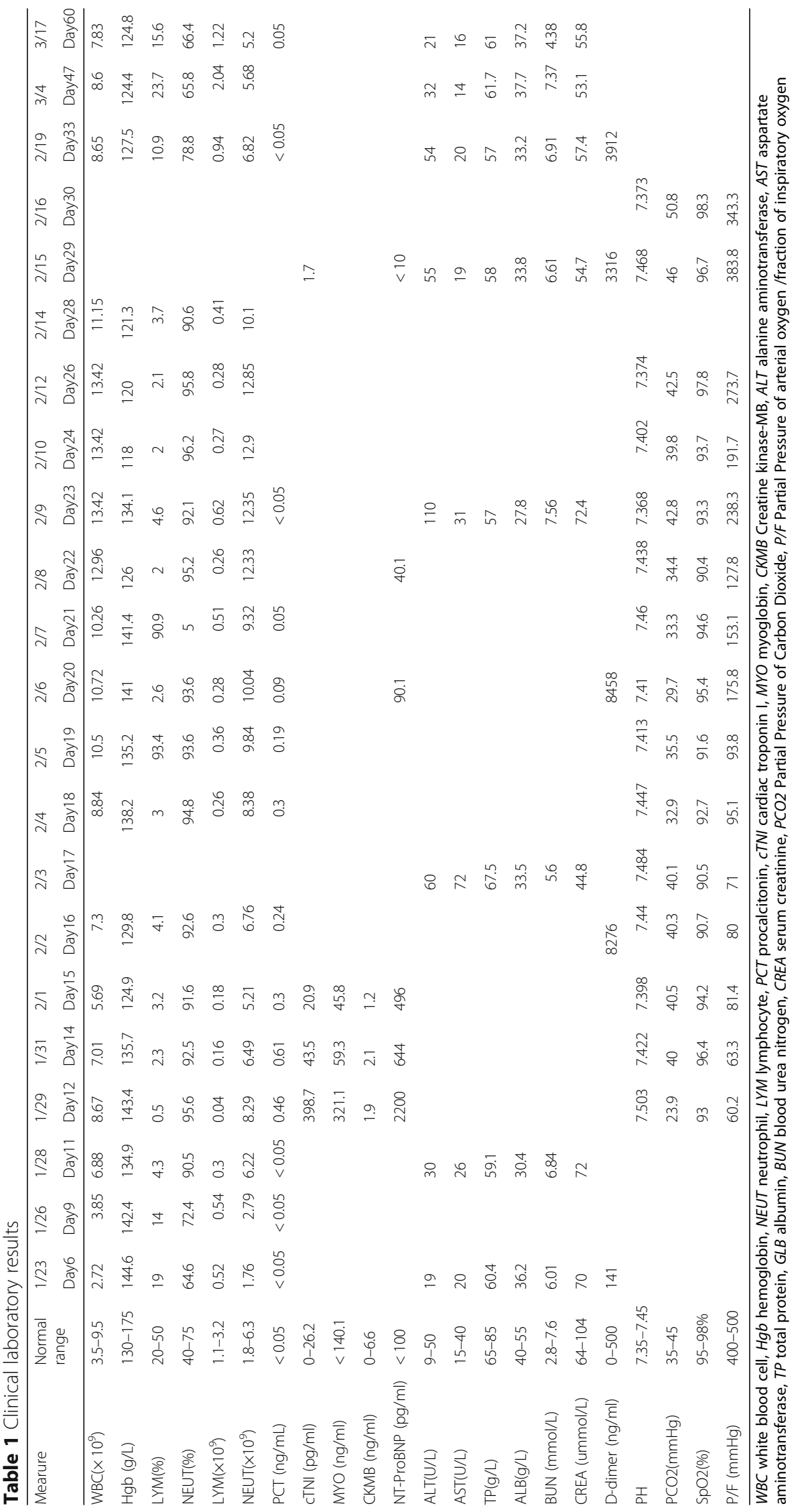


timely management the pneumothorax can be fatal. This means that manifestations and treatment methods of COVID-19 pneumonia with pneumothorax require careful consideration.

There are already several case reports about this pneumothorax related to COVID-19 [7-9], however they were not presented in recovery time. In this case, the patient did not have a history of any underlying pulmonary disease. Laboratory examinations, symptoms and chest CT were similar to general population without pneumothorax. The onset of the pneumothorax of this patient occurred on the day 29 after the initial diagnosis of COVID-19, which suggested that a sustained period of extensive lung injury may increase susceptibility of pneumothorax. It is crucial for clinicians to pay attention to the appearance of spontaneous pneumothorax which sometimes would occur unpredictably in delayed feature, especially patients with severe pulmonary damage for a long course. Given symptoms may be subtle, respiratory monitor and early CT scan can be of a great benefit. Secondly, this case highlights the importance for immediate and active treatment [10]. In the present case, we mainly adopted thoracic closed drainage and offered supplemental oxygen. What's more, the follow-up CT is needed to observe the conversion of pulmonary damage and to avoid recurrence of the pneumothorax.

This is a first report of a COVID-19 pneumonia patient with spontaneous pneumothorax in Wuhan, which illustrates several aspects including the clinical features and therapeutic course. Following an active treatment regimen consisting of thoracic closed drainage and supplemental oxygen therapy, the patient recovered well. However, because of the limited case, predisposing factors, onset time of COVID-19 pneumonia patient with spontaneous pneumothorax occurring, and treatment protocol deserve further research.

\section{Abbreviations \\ COVID-19: Coronavirus disease 2019; SARS-COV-2: Severe acute respiratory syndrome coronavirus 2; CT: Computed tomography; GGO: Ground-glass opacities; GIW: General isolation ward; ICU: Intensive Care Unit; NIMV: Non- invasive mechanical ventilation; HFNC: High-flow nasal cannula; CPAP/ PSV: Continuous positive airway pressure-pressure support ventilation; PEEP: Positive end expiratory pressure}

\section{Acknowledgments}

Not applicable.

\section{Authors' contributions}

HQP and XXC contributed to the conceptions and design; YTT and ZYP contributed to the data analyses; XXC and GQZ contributed to the data interpretation and manuscript writing. All authors have read and approved the manuscript.

\section{Funding}

None.

\section{Availability of data and materials}

All data generated or analyzed during this study are included in the published article.
Ethics approval and consent to participate

The study is approved by the Medical Ethics Committees, Zhongnan Hospital of Wuhan University (No.2020099 K) and the patient is consent to participate.

\section{Consent for publication}

Written informed consent for publication of the clinical details and/or clinical images was obtained from the patient.

\section{Competing interests}

The authors declare that they do not have any competing interests.

\section{Author details}

'Department of Geriatrics, Renmin Hospital of Wuhan University, Wuhan University, Wuhan, China. ${ }^{2}$ Department of Respiratory and Critical Care Medicine, Zhongnan Hospital of Wuhan University, Wuhan 430071, China. ${ }^{3}$ Department of Clinical Laboratory, Zhongnan Hospital of Wuhan University, Wuhan 430071, China. ${ }^{4}$ Department of Critical Care Medicine, Zhongnan Hospital of Wuhan University, 169 Eastlake Rd., Wuchang district, Wuhan 430071, Hubei province, China.

Received: 13 May 2020 Accepted: 30 August 2020

Published online: 09 September 2020

\section{References}

1. Wu Z, McGoogan JM. Characteristics of and important lessons from the coronavirus disease 2019 (COVID-19) outbreak in China: summary of a report of 72314 cases from the Chinese Center for Disease Control and Prevention. JAMA.2020 https://doi.org/10.1001/jama.2020.2648.

2. Zhu N, Zhang D, Wang W, et al. China novel coronavirus investigating and research team. A novel coronavirus from patients with pneumonia in China, 2019. N Engl J Med. 2020;382:727-33.

3. World Health Organization. Coronavirus disease 2019 (COVID-19) Situation Report -72[EB/OL]. [2020-04-01]. https://www.who.int/emergencies/ diseases/novel-coronavirus-2019/situation-reports.

4. Guo YR, Cao QD, Hong ZS, et al. The origin, transmission and clinical therapies on coronavirus disease 2019 (COVID-19) outbreak - an update on the status. Military Medical Research. 2020;7(1):11.

5. Lu R, Zhao X, Li J, et al. Genomic characterization and epidemiology of 2019 novel coronavirus: implications for virus origins and receptor binding. Lancet. 2020;395(10224):565-74.

6. Sihoe AD, Wong RH, Lee AT, et al. Severe acute respiratory syndrome complicated by spontaneous pneumothorax. Chest. 2004;125(6):2345-51.

7. Wang W, Gao R, Zheng Y, Jiang L. COVID-19 with spontaneous pneumothorax, pneumomediastinum and subcutaneous emphysema. J Travel Med. 2020;27(5):taaa062.

8. Ucpinar BA, Sahin C, Yanc U. Spontaneous pneumothorax and subcutaneous emphysema in COVID-19 patient: case report. J Infect Public Health. 2020;13(6):887-9.

9. Xiang C, Wu G. SARS-CoV-2 pneumonia with subcutaneous emphysema, mediastinal emphysema, and pneumothorax: a case report. Medicine. 2020; 99(20):e20208.

10. Bintcliffe O, Maskell N. Spontaneous pneumothorax. BMJ. 2014;348:g2928.

\section{Publisher's Note}

Springer Nature remains neutral with regard to jurisdictional claims in published maps and institutional affiliations.
Ready to submit your research? Choose BMC and benefit from:
- fast, convenient online submission
- thorough peer review by experienced researchers in your field
- rapid publication on acceptance
- support for research data, including large and complex data types
- gold Open Access which fosters wider collaboration and increased citations
- maximum visibility for your research: over $100 \mathrm{M}$ website views per year
At BMC, research is always in progress.
Learn more biomedcentral.com/submission 